Article

\title{
High Performance Redox Initiating Systems Based on the Interaction of Silane with Metal Complexes: A Unique Platform for the Preparation of Composites
}

\author{
Ahmad Arar ${ }^{1,2}$, Haifaa Mokbel ${ }^{1,2}$, Frédéric Dumur ${ }^{3}$ (1) and Jacques Lalevée ${ }^{1,2, *}$ \\ 1 Université de Haute-Alsace, CNRS, IS2M UMR 7361, F-68100 Mulhouse, France; \\ ahmad.mh.arar@gmail.com (A.A.); haifaa.mokbel@uha.fr (H.M.) \\ 2 Université de Strasbourg, Strasbourg F-67081, France \\ 3 Aix Marseille Univ, CNRS, ICR UMR 7273, F-13397 Marseille, France; frederic.dumur@univ-amu.fr \\ * Correspondence: Jacques.lalevee@uha.fr
}

Received: 20 March 2020; Accepted: 30 March 2020; Published: 31 March 2020

check for updates

\begin{abstract}
Currently, Redox Initiating Systems (RISs) of Free Radical Polymerization (FRP) are mainly based on the interaction of aromatic amines with peroxides (e.g., dibenzoyl peroxide (BPO)) that can be both toxic and unstable. In the present work, we aim to replace these hazardous substances in new RIS that can be peroxide-free and amine-free. Our redox two components (2K) initiating system is based on diphenylsilane (DPS) as reducing agent combined with different metal complexes ( $\mathrm{Mn}(\mathrm{acac})_{2}$, $\mathrm{Cu}(\mathrm{AAEMA})_{2}$ or $\left.\mathrm{Fe}(\mathrm{acac})_{3}\right)$ as oxidizing agents. For the new proposed RIS, an excellent reactivity is found for the polymerization of benchmark methacrylate monomers under mild conditions (redox polymerization done under air and at room temperature); remarkably, it is also possible to finely control the gel time. Different techniques (optical pyrometry, Real-Time FTIR spectroscopy, Cyclic Voltammetry and Electron Spin Resonance (ESR)) were used to follow the polymerization processes but also to shed some light on the new redox chemical mechanisms.
\end{abstract}

Keywords: redox systems; $2 \mathrm{~K}$ systems; composite materials; free radical polymerization

\section{Introduction}

Redox initiated Free radical polymerization (FRP) is a very well-established technique for polymer production due to its applicability under mild conditions [1-5]. Simply put, the mixing of reducing and oxidizing agents initially separated in two cartridges leads to the formation of free radicals through a redox mechanism to initiate the polymerization process. Such redox systems are already used in widespread research fields: adhesives, composites, biomedical materials, etc. However, the current challenge is to replace the toxic and poorly stable redox agents by safer alternatives [6-11]. More particularly, the broadly used dibenzoyl peroxide (BPO)/aromatic amine (e.g., 4- $N, N$-trimethylaniline (4-N,N-TMA)) initiating system is characterized by i) the toxicity issue raised by the use of an amine combined with ii) the issue resulting from peroxides handling and storage and pressing regulations on peroxides. To overcome the aforementioned risks, we propose here new redox initiating systems (RISs) which can be more stable and eco-friendlier [12-25]. Remarkably, these amine-free and peroxide-free systems can be efficient under mild conditions-under air-with controllable gel time. Precisely, diphenylsilane (DPS), selected as a potential reduction agent [26], is originally explored in combination with three oxidative metal complexes $\left(\mathrm{Mn}(\mathrm{acac})_{2}\right.$ or $\mathrm{Fe}(\mathrm{acac})_{3}$ or $\mathrm{Cu}(\mathrm{AAEMA})_{2}$; with acac $=$ acetylacetonate and AAEMA = methacryloyloxyethylacetoacetate). All these redox agents have great advantages compared to peroxide (e.g., BPO) because they are stable in monomers at room temperature. As an example of the high interest of the new proposed RISs, the polymerization of prepregs (glass or carbon fibers impregnated by organic monomers) is shown for the access to composites. 


\section{Results}

\subsection{Redox Initiating Systems (RISs) using DPS/Metal Complex Combination}

The different chemicals used for the redox initiating systems are gathered in Scheme 1 and the chemical structure of the benchmark methacrylate monomers selected for this study are depicted in Scheme 2. We are interested in polymerization under air; indeed, redox initiating systems are used in many applications under air. Therefore, the resin 1 (Scheme 2), specifically developed in previous works [24,25] (with an adapted viscosity) for polymerization under air, has been used.

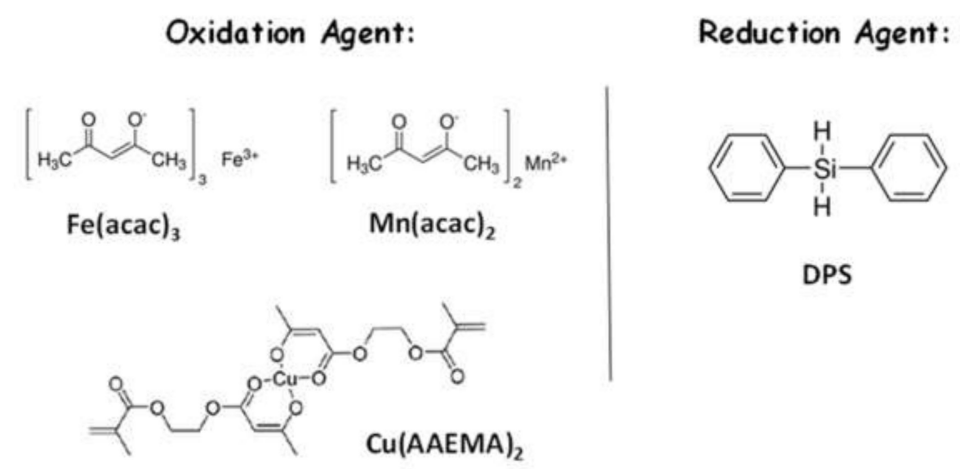

Scheme 1. Chemicals used for the redox Free Radical Polymerization (FRP) initiation in this study.

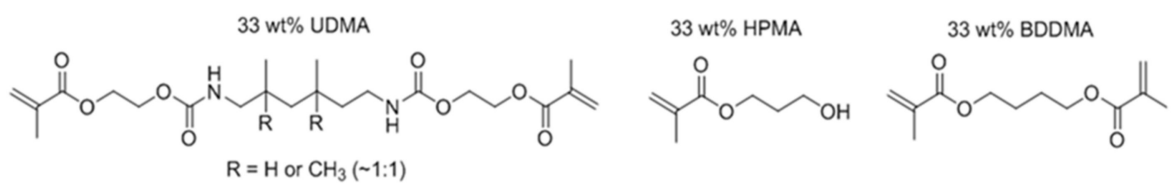

Scheme 2. Benchmark methacrylate monomer blend (noted resin 1).

First, different metal complexes (based on $\mathrm{Fe}, \mathrm{Cu}$ and $\mathrm{Mn}$ ) were used in RIS in combination with DPS for the polymerization of the benchmark methacrylate monomer. The polymerization efficiencies of these various redox systems followed by optical pyrometry are depicted in Figure 1. Interestingly, a rather similar reactivity is observed for both metal complexes $\mathrm{Cu}(\mathrm{AAEMA})_{2}$ and $\mathrm{Mn}(\mathrm{acac})_{2}$ (Figure $1 \mathrm{~A}$ for $\mathrm{Cu}(\mathrm{AAEMA})_{2}$ and Figure 1B for $\left.\mathrm{Mn}(\mathrm{acac})_{2}\right)$. A longer gel time is obtained (600-800 s) for a high metal content ( 2 wt \%) which is interesting when a delayed curing (work time) is required. However, for a high DPS content $(2 \% w / w)$, the redox polymerization can be very fast: the gel time decreased by up to 150-200 s. Remarkably, the gel time can be controlled with the concentrations of DPS and metal complexes. Tack-free surfaces are obtained in all cases, showing the ability of these RISs to overcome the classical oxygen inhibition observed for the well-established dibenzoyl peroxide (BPO)/aromatic amine system [24]. The polymerization of methylmethacrylate (MMA) does not work in our conditions; this behavior can be ascribed to the very strong oxygen inhibition conditions (the polymerization is carried out under air) associated with very low viscosity monomers. 
(A)

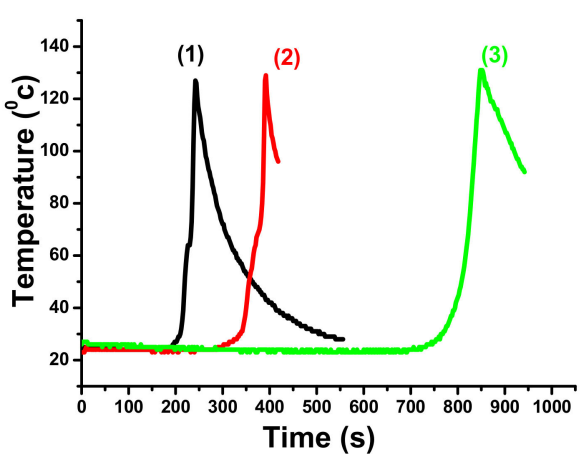

(B)

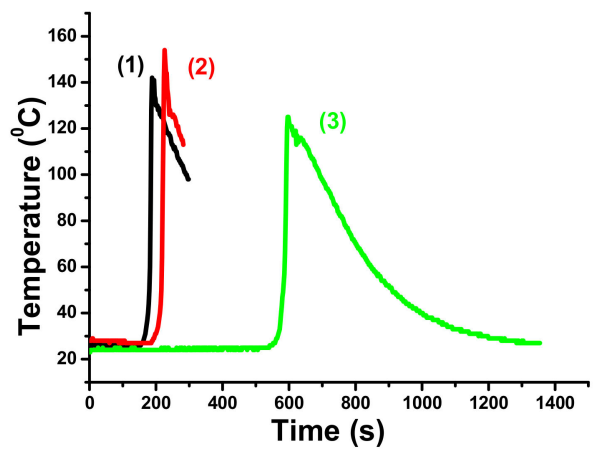

Figure 1. Optical pyrometric measurements (temperature vs. time after mixing; $4 \mathrm{~mm}$ thick sample) under air in resin 1 for Redox FRP for (A): (1) Cu(AAEMA) $2 /$ DPS (0.5/2 \%wt), (2) Cu(AAEMA) $2 / D P S$ (1/1 \%wt), (3) Cu(AAEMA) $2 / \mathrm{DPS}(2 / 0.5 \% w t)$ and (B): (1) Mn(acac) $2 / \mathrm{DPS}(0.5 / 2 \% w t),(2) \mathrm{Mn}(\mathrm{acac})_{2} / \mathrm{DPS}$ $(1 / 1 \% w t),(3) \mathrm{Mn}(\mathrm{acac})_{2} / \mathrm{DPS}(2 / 0.5 \% \mathrm{wt})$ initiating systems.

4-N,N-trimethylaniline (4-N,N-TMA), a benchmark amine used as reduction agent, does not show any activity in combination with the present metal complexes (no polymerization observed) showing the unique role of DPS for these redox processes.

The $\mathrm{Fe}(\mathrm{acac})_{3} / \mathrm{DPS}$ system was not found to be very efficient at initiating the polymerization under air. For example, $1000 \mathrm{~s}$ were necessary for curing with a lower temperature (only $47^{\circ} \mathrm{C}$, Figure $2 \mathrm{~B}$ ). The results obtained here for $\mathrm{Cu}(\mathrm{AAEMA})_{2}, \mathrm{Mn}(\mathrm{acac})_{2}$ and $\mathrm{Fe}(\mathrm{acac})_{3}$ with DPS were compared with those obtained with $\mathrm{Mn}(\mathrm{acac})_{3}$ that has been proposed in other redox systems [23] (Figure 2A). Interestingly, $\mathrm{Cu}(\mathrm{AAEMA})_{2}$ and $\mathrm{Mn}(\mathrm{acac})_{2}$ are characterized by a good efficiency (similar to that observed for $\mathrm{Mn}(\mathrm{acac})_{3}$ ) (Figure 2A). The polymerization parameters for the different redox systems are gathered in Table 1.

(A)

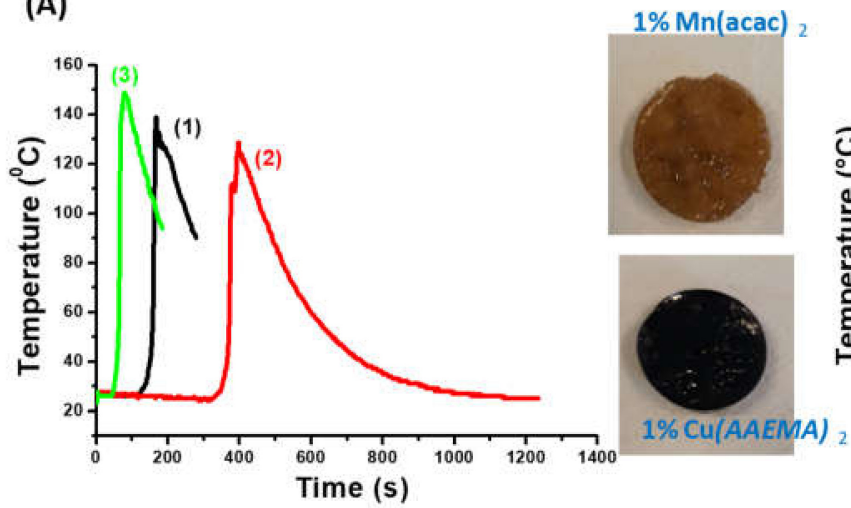

(B)

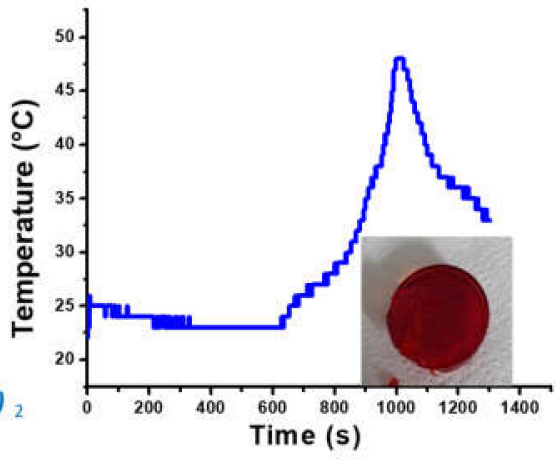

Figure 2. Optical pyrometric measurements (temperature vs. time after mixing; $4 \mathrm{~mm}$ thick sample) under air in resin 1 for Redox FRP of (A): (1) Mn(acac) $)_{2} /$ diphenylsilane (DPS) (1/1\%wt), (2) $\mathrm{Cu}(\mathrm{AAEMA})_{2} / \mathrm{DPS}(1 / 1 \% \mathrm{wt})$, (3) Mn(acac) $)_{3} / \mathrm{DPS}(1 / 1 \% \mathrm{wt})$ and (B) Fe(acac) $)_{3} / \mathrm{DPS}(1 / 1.4 \mathrm{wt} \%)$ initiating system.

These polymerization processes were also followed by Real-Time FTIR spectroscopy. Remarkably, very high final methacrylate function conversions (e.g., $\mathrm{FC}=98 \%$ - Figure $3 \mathrm{~A}$ and Table 1 ) were found under air using the two-component Metal complex/DPS redox systems (1/1 wt \%). The recorded FTIR spectra before and after polymerization which showed a full decrease of the characteristic $\mathrm{C}=\mathrm{C}$ peak at $6160 \mathrm{~cm}^{-1}$ are depicted in Figure 3B. 
(A)

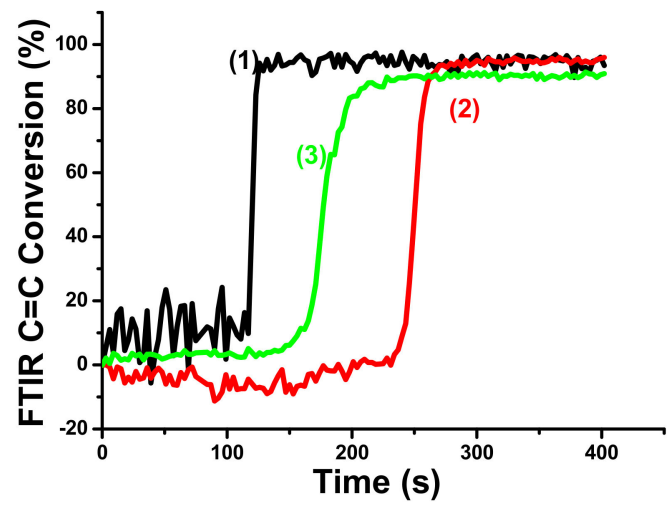

(B)

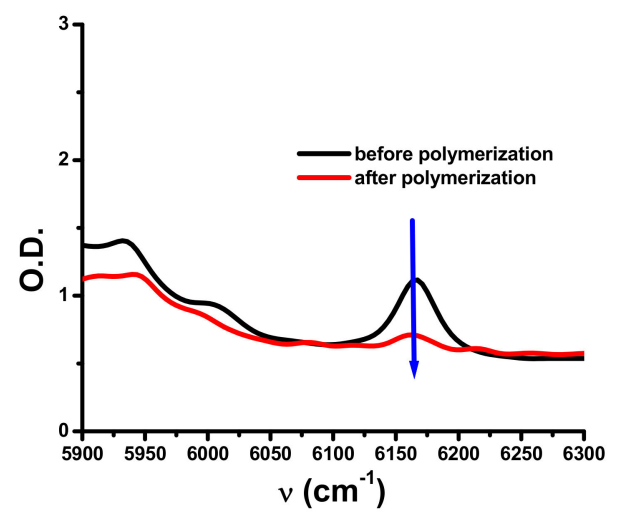

Figure 3. (A) Redox Polymerization profiles (methacrylate $\mathrm{C}=\mathrm{C}$ function conversion vs. time; mixing for $\mathrm{t}=0 \mathrm{~s}$ ) measured in Real-time Fourier Transform Infrared (RT-FTIR) for the resin 1; $1.4 \mathrm{~mm}$ thick samples, under air for: (1) Mn(acac) 3 /DPS (1/1 \%wt), (2) Mn(acac) 2 /DPS (1/1 \%wt), (3) Cu(AAEMA) 2 /DPS (1/1 $\% w t)$. (B) IR spectra recorded before and after polymerization using $\mathrm{Cu}(\mathrm{AAEMA})_{2} / \mathrm{DPS}(1 / 1 \mathrm{wt} \%)$.

Similar trends are observed between pyrometry and RT-FTIR data. The slight differences of gel times between both techniques can be ascribed to the different thicknesses of the samples $(4 \mathrm{~mm}$ in pyrometry vs. $1.4 \mathrm{~mm}$ in RT-FTIR experiments) leading to different oxygen inhibition behaviors.

\subsection{Potential Photoactivation of the New Proposed RIS (DPS/Mn(acac) ${ }_{2}$ )}

The possible photoactivation of the RIS was checked upon irradiation with an LED at $405 \mathrm{~nm}\left(230 \mathrm{~mW} / \mathrm{cm}^{2}\right)$. However, it is found that this DPS/Mn(acac) $)_{2}$ RIS does not show any significant photoactivation in terms of exothermicity and gel time (Figure 4). This suggests that the photo-induced redox process remains a minor pathway for the FRP compared to the dark redox process. The same behavior is also obtained for $\mathrm{Cu}(\mathrm{AAEMA})_{2}$ where no effect of photoactivation is observed upon irradiation.

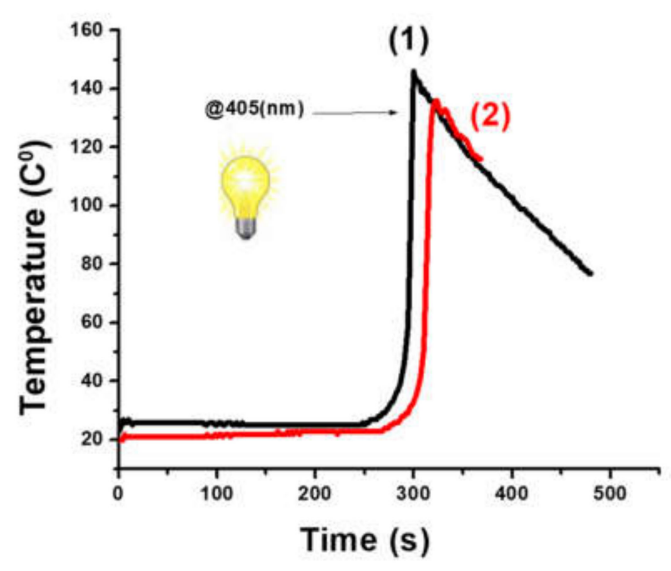

Figure 4. Optical pyrometric measurements (temperature vs. time after mixing; $4 \mathrm{~mm}$ thick sample) under air using a Redox Initiating System (RI)S Mn(acac) 2 /DPS (1/1 wt\%); (1) with light (LED at $405 \mathrm{~nm}$ ) and (2) without light. 


\subsection{Stability upon Storage}

Remarkably, an excellent stability of the proposed RIS was found in monomers. For example, $\mathrm{Mn}(\mathrm{acac})_{2}, \mathrm{Cu}(\mathrm{AAEMA})_{2}$ or DPS formulations showed a stability of 7 days in accelerated aging experiments (when stored in an oven at $50{ }^{\circ} \mathrm{C}$ ). Interestingly, the gel time is not significantly affected by storage compared to that obtained for fresh formulations (Figure 5). This can extend the areas of application of redox induced polymerization. $\mathrm{Mn}(\mathrm{acac})_{3}$ was the best candidate in terms of reactivity (Figure 2) but is not stable in accelerated aging experiments (Figure 5C). In contrast, the other metal complexes ( $\mathrm{Cu}(\mathrm{AAEMA})_{2}$ and $\left.\mathrm{Mn}(\mathrm{acac})_{2}\right)$ showed both excellent reactivity and stability. Therefore, the lack of stability of $\mathrm{Mn}(\mathrm{acac})_{3}$ in monomers at $50^{\circ} \mathrm{C}$ can limit the use of this metal complex.

(A)

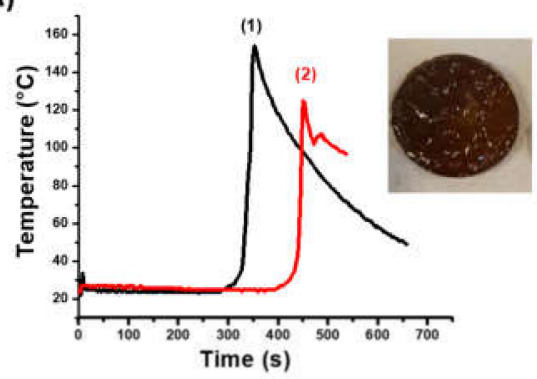

(B)

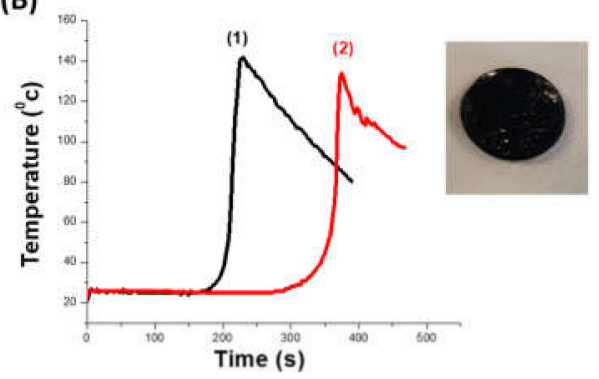

(C)

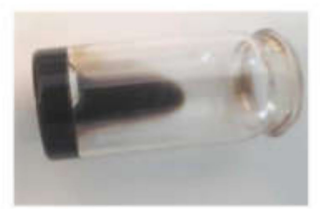

Not stable

Figure 5. Optical pyrometric measurements (temperature vs. time after mixing, $4 \mathrm{~mm}$ thick sample) under air in resin 1 for Redox FRP of (A) (1) Mn(acac) 2 /DPS (1/1 wt \%) fresh formulations and (2) $\mathrm{Mn}(\mathrm{acac})_{2} / \mathrm{DPS}(1 / 1 \mathrm{wt} \%)$ after 6 days of storage at $50{ }^{\circ} \mathrm{C}$; (B) (1) Cu(AAEMA) $)_{2} / \mathrm{DPS}(1 / 1 \mathrm{wt} \%)$ fresh formulations and (2) $\mathrm{Cu}(\mathrm{AAEMA})_{2} / \mathrm{DPS}(1 / 1 \mathrm{wt} \%)$ after 6 days of storage at $50{ }^{\circ} \mathrm{C} ;(\mathbf{C}) \mathrm{Mn}(\mathrm{acac})_{3}(1$ $\mathrm{wt} \%)$ after $48 \mathrm{~h}$ of storage in resin 1 at $50{ }^{\circ} \mathrm{C}$.

\subsection{Application to the Preparation of Composites}

Finally, we propose to access composites as an application of the new proposed RISs which are characterized by both 1) stability in accelerated aging and 2) highly workable systems (high reactivity and adjusted gel time). Composites materials are highly recommended for different fields as they allow the combination of good mechanical properties with the high flexibility of the polymerization processes. The proposed RISs can fully meet this requirement with a curing time that can be controlled. By curing one layer of prepregs (carbon fibers; thickness $\sim 0.2 \mathrm{~mm}$ or glass fibers; thickness $\sim 0.6 \mathrm{~mm}$ ) impregnated with organic resin, a good polymerization process is observed when using Mn(acac) $2 / \mathrm{DPS}$ $(1 / 1 \mathrm{wt} \%)$. This system is efficient for the preparation of composites where only a few minutes are enough to reach tack-free surfaces (for both the surface and the bottom of the sample) (Figure 6). For composites, lower temperatures are reached as part of the heat released is absorbed by the fibers (Figure 6A). 
(A)

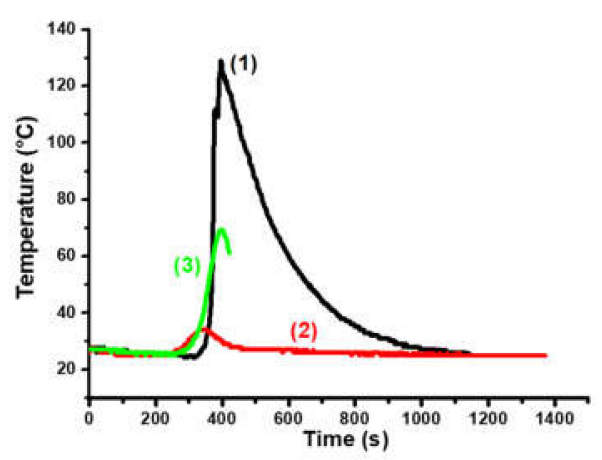

(B)

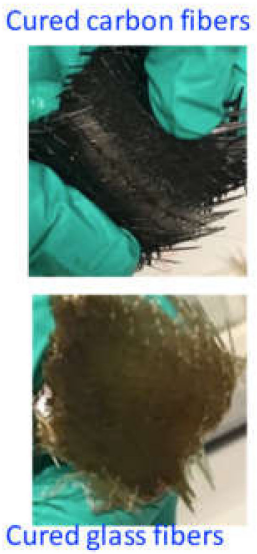

Figure 6. (A) Optical pyrometric measurements for the curing of prepregs (glass fibers or carbon fibers/Resin 1 composites) in the presence of (1) Mn(acac) $2 / \mathrm{DPS}$ (1/1\%wt) (without fibers), (2) Mn(acac) 2 /DPS (1/1 \%wt) (carbon fibers), (3) Mn(acac) $2 /$ DPS (1/1\%wt) (glass fibers) and (B) Photos for impregnated glass fibers taken after mixing with redox initiating system for $50 \%$ glass or carbon fibers and $50 \%$ of organic resin.

\section{Discussion}

In the frame of a redox initiated polymerization, as a general rule, a higher reduction potential of the oxidizing agent (in our case of the metal complex) must lead to a better reactivity. The reduction potentials of the metal complexes follow this order: Cu(AAEMA $)_{2}>\operatorname{Mn}(\text { acac })_{3}>\operatorname{Mn}(\text { acac })_{2}$ (See Table 1, Figure 7). This order is not in agreement with the experimental trend in redox processes $\left(\mathrm{Mn}(\mathrm{acac})_{3}>\mathrm{Mn}(\mathrm{acac})_{2}>\mathrm{Cu}(\mathrm{AAEMA})_{2}\right)$ showing that a more complex mechanism than a pure electron transfer occurs for the formation of free radicals (see the ESR results below).

Table 1. Data of polymerization using different redox systems for the benchmark monomer blend.

\begin{tabular}{|c|c|c|c|c|c|c|}
\hline System & Gel Time (s) & $\underset{{ }^{\circ} \mathrm{C}}{\operatorname{Maximum} \mathrm{T}}$ & $\begin{array}{l}\text { Surface } \\
\text { Curing }\end{array}$ & $\begin{array}{c}\text { Final } \mathrm{C}=\mathrm{C} \\
\text { Conversion }(\%)\end{array}$ & $\begin{array}{l}E_{\text {red }} \\
(V)\end{array}$ & $\Delta \mathrm{G}[\mathrm{eV}]$ \\
\hline $\begin{array}{c}\mathrm{Mn}(\text { acac })_{2} / \\
\text { DPS } \\
1 / 1 \mathrm{wt} \%\end{array}$ & 110 & 140 & Tack-free & $98 \%$ & -1.07 & 2.47 \\
\hline $\begin{array}{c}\mathrm{Cu}(\mathrm{AAEMA})_{2} \\
/ \mathrm{DPS} \\
1 / 1 \mathrm{wt} \%\end{array}$ & 380 & 130 & Tack-free & $90 \%$ & -0.65 & 2.05 \\
\hline $\begin{array}{c}\mathrm{Fe}(\text { acac })_{3} / \\
\text { DPS } \\
1 / 1 \mathrm{wt}^{\%} \%\end{array}$ & 900 & 45 & Tacky & n.d. & n.d. & n.d. \\
\hline $\begin{array}{c}\mathrm{Mn}(\mathrm{acac})_{3} / \\
\mathrm{DPS} \\
1 / 1 \mathrm{wt} \%\end{array}$ & 155 & 142 & Tack-free & $98 \%$ & -0.85 & 2.25 \\
\hline
\end{tabular}

n.d.: not determined; $\Delta \mathrm{G}=$ Eox-Ered (Eox $(\mathrm{DPS})=1.4 \mathrm{~V})$, Eox of DPS and Ered of different metal complexes have been determined by cyclic voltammetry (Figure 7). 
(A)

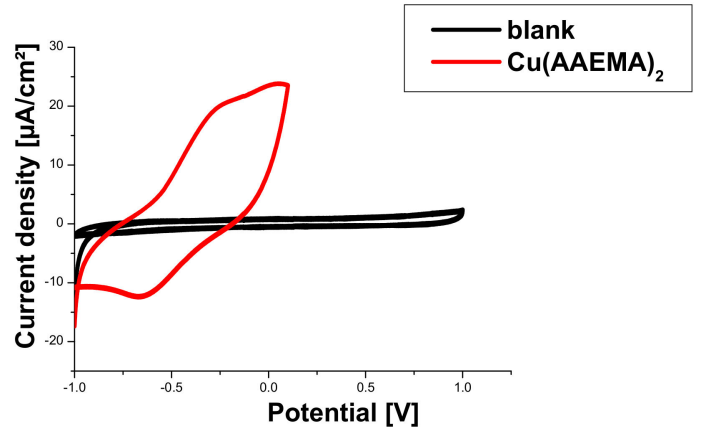

(B)

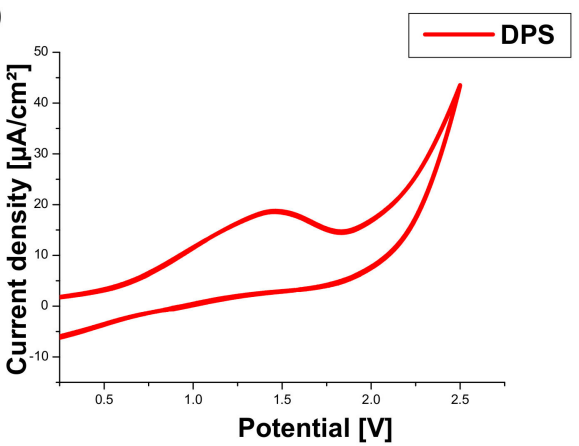

Figure 7. Cyclic voltammetry (potential vs. saturated calomel electrode (SCE)) experiments in acetonitrile $(\mathrm{ACN})$ (containing $0.2 \mathrm{M}$ tetrabutylammonium hexafluorophosphate, $0.1 \mathrm{~V} / \mathrm{s}$ ) for the determination of $(\mathrm{A})$ reduction potential of $\mathrm{Cu}(\mathrm{AAEMA})_{2}$ and $(\mathbf{B})$ oxidation potential of DPS.

For a better understanding of the reactivity of redox system, ESR and ESR-spin trapping experiments were carried out for DPS/metal complex systems (Figure 8). Using phenyl-tert-butyl nitrone $(\mathrm{PBN})$ as the spin trap agent, free radical adducts are detected after mixing of DPS and $\mathrm{Mn}(\mathrm{acac})_{2}$ (Figure $8 \mathrm{~A}$ ) or $\mathrm{Cu}(\mathrm{AAEMA})_{2}$ (Figure $8 \mathrm{~B}$ ) in tert-butylbenzene and under $\mathrm{N}_{2}$. The radical adducts are characterized by the following hyperfine coupling constants: i) aN $=14.8 \mathrm{G} ; \mathrm{aH}=5.3 \mathrm{G}$ and ii) $\mathrm{aN}=14.9 \mathrm{G} ; \mathrm{aH}(2)=7.4 \mathrm{G}$ that can be assigned to the known $\mathrm{Ph}_{2} \mathrm{Si} \bullet \mathrm{H} / \mathrm{PBN}$ and $\mathrm{H} \bullet / \mathrm{PBN}$ adducts, respectively $[27,28]$.
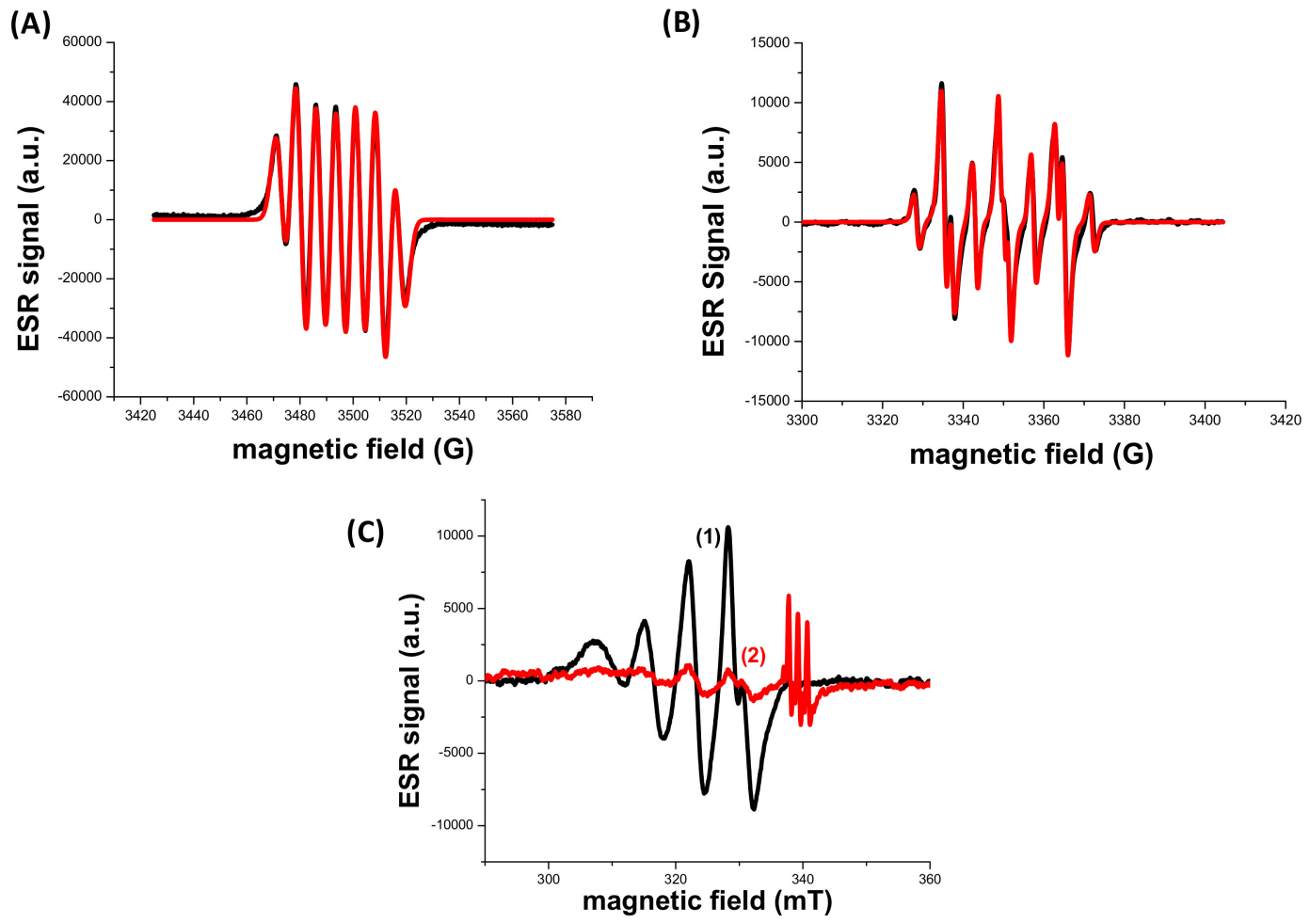

Figure 8. Electron Spin Resonance (ESR)-spin trapping experiment using $[\mathrm{PBN}]=10^{-2} \mathrm{M}$ (as spin trap agent); for the mixing of [DPS] $=10^{-1} \mathrm{M}$ with (A) $\mathrm{Mn}(\text { acac })_{2}$, (B) $\mathrm{Cu}(\mathrm{AAEMA})_{2}$ simulated (red) and experimental (black) spectra, (C) Reduction of Cu (AAEMA) $)_{2} ;(1)$ without DPS and (2) with DPS in tert-butylbenzene; under $\mathrm{N}_{2}$. 
This suggests the redox reaction ( $\mathrm{r} 1$ ) between DPS and metal complex.

$$
\mathrm{Ph}_{2} \mathrm{SiH}_{2}+\operatorname{Metal}^{\mathrm{n}}(\mathrm{acac})_{\mathrm{x}} \rightarrow \rightarrow \rightarrow \mathrm{Ph}_{2} \mathrm{Si} \bullet \mathrm{H}+\mathrm{H} \bullet+\mathrm{Metal}^{\mathrm{n}-1}(\text { acac })_{\mathrm{y}}
$$

The radicals generated in ( $\mathrm{r} 1)$ can be assumed as the initiating species for the FRP processes observed above.

More interestingly, for $\mathrm{Cu}(\mathrm{AAEMA})_{2}$, the characteristic $\mathrm{Cu}$ (II) spectrum (Figure $8 \mathrm{C}$ ) strongly decreases in presence of DPS (curve 1 vs. curve 2) clearly showing the reduction of $\mathrm{Cu}$ (II) to $\mathrm{Cu}$ (I) by DPS in agreement with $\mathrm{r} 1$. Indeed, $\mathrm{Cu}(\mathrm{II})$ can be observed in ESR but $\mathrm{Cu}(\mathrm{I})$ is ESR silent.

\section{Materials and Methods}

\subsection{Chemical Compounds}

All chemicals were purchased with high purity and used as received (Scheme 1). Diphenylsilane (DPS) and $\mathrm{Mn}(\mathrm{acac})_{2}$ were purchased from TCI-Europe. $\mathrm{Fe}(\mathrm{acac})_{3}$ was obtained from Sigma-Aldrich. $\mathrm{Cu}$ (II)(methacryloyloxyethylacetoacetate) ${ }_{2}$ will be noted $\mathrm{Cu}(\mathrm{AAEMA})_{2}$ and was purchased from Chem Cruz. The efficiency of the different RISs was checked in a benchmark methacrylate monomer blend (noted resin 1) having an adapted viscosity (0.053 Pa.s) and containing 33.3\% UDMA (urethane dimethacrylate) 33.3\% HPMA (hydroxypropyl methacrylate) and 33.3\% BDDMA (butanediol dimethacrylate) (Scheme 2).

\subsection{Two Cartridges System Used for Redox Experiments}

All redox formulations were prepared in bulk in two separate cartridges: a first cartridge with the DPS and the other one containing the Metal complex (Cu(AAEMA $)_{2}, \mathrm{Mn}(\mathrm{acac})_{2}$ or Fe (acac $\left.)_{3}\right)$. A 1:1 Sulzer mixpac mixer was used to mix the two cartridges at the beginning of each polymerization experiment. As all polymerization experiments were performed at room temperature $\left(\sim 20-25{ }^{\circ} \mathrm{C}\right)$ and under air, an oxygen inhibition can be expected, particularly for the surface in direct contact with air [20].

\subsection{Redox Polymerization in Bulk Followed by Optical Pyrometry}

Optical pyrometry was used to follow polymerization reactions: temperature vs. time profiles were followed using an Omega OS552-V1-6 infrared thermometer (Omega Engineering, Inc., Stamford, $\mathrm{CT}$ ) having a sensitivity of $\pm 1^{\circ} \mathrm{C}$ for $2 \mathrm{~g}$ samples (thickness $\sim 4 \mathrm{~mm}$ ). The redox initiator contents will be given in weight with respect to the monomer in the final blend (wt\%). The optical pyrometry is used to check the gel time, i.e., the time required from a two-component mixing to go from a fluid/viscous state to a gel/solid one.

\subsection{RT-FTIR Spectroscopy}

A JASCO 4100 Real-time Fourier Transform Infrared Spectrometer (RT-FTIR) was used to follow the evolution of the methacrylate peak functionality for the thick samples $(1.4 \mathrm{~mm})$ in the near-infrared range from 6130 to $6200 \mathrm{~cm}^{-1}$.

\subsection{Electron Spin Resonance (ESR) Spin Trapping (ESR-ST)}

Electron spin resonance-spin trapping experiments were carried out using an X-band spectrometer (Magnettech MS400). The radicals were observed at room temperature under nitrogen saturated medium in toluene. N-tert-butyl-phenylnitrone (PBN) was used as a spin trap agent in a similar way as described in other works [21-25]. ESR spectra simulations were carried out using WINSIM software. 


\subsection{Cyclic Voltammetry}

The reduction potentials ( $E_{\text {red }}$ vs. SCE) of the different metal complexes were determined by cyclic voltammetry in ACN using tetrabutylammonium hexafluorophosphate $(0.1 \mathrm{M})$ as a supporting electrolyte. The procedure was reported in detail in [21-25].

\section{Conclusions}

In this paper, new redox initiating systems are proposed for the free radical polymerization of methacrylate monomers. Contrary to the $\mathrm{Mn}(\mathrm{acac})_{3}$, which is not very stable in accelerated aging conditions, both $\mathrm{Mn}(\mathrm{acac})_{2}$ and $\mathrm{Cu}(\mathrm{AAEMA})_{2}$ showed excellent reactivity and stability. Composites materials based on glass or carbon fibers can be produced using these proposed systems. Other peroxide-free and amine-free systems that can be activated by light will be proposed in forthcoming papers to gather the advantages of photopolymerization and redox polymerization.

Author Contributions: Conceptualization, J.L.; methodology, J.L., H.M.; validation, J.L., A.A., H.M.; formal analysis, J.L., A.A., H.M.; data curation, A.A.; writing-original draft preparation, J.L., A.A., H.M., F.D.; writing-review and editing, J.L., A.A., H.M., F.D.; supervision, J.L. All authors have read and agreed to the published version of the manuscript.

Funding: This research received no external funding.

Conflicts of Interest: The authors declare no conflict of interest.

\section{References}

1. Yagci, Y.; Mishra, M. Handbook of Vinyl Polymers - Radical Polymerization and Technology; Wiley: New York, NY, USA, 2009; pp. 307-344.

2. Green, W.A. Industrial Photoinitiators: A Technical Guide; CRC Press: Boca Raton, FL, USA, 2010.

3. Dadashi-Silab, S.; Doran, S.; Yagci, Y. Photoinduced Electron Transfer Reactions for Macromolecular Syntheses. Chem. Rev. 2016, 116, 10212-10275. [CrossRef] [PubMed]

4. Corrigan, N.A.; Shanmugam, S.; Xu, J.; Boyer, C. Photocatalysis in organic and polymer synthesis. Chem. Soc. Rev. 2016, 45, 6165-6212. [CrossRef] [PubMed]

5. Garra, P.; Dietlin, C.; Morlet-Savary, F.; Dumur, F.; Gigmes, D.; Fouassier, J.; Lalevée, J. Photopolymerization processes of thick films and in shadow areas: A review for the access to composites. Polym. Chem. 2017, 8, 7088-7101. [CrossRef]

6. Kwon, T.-Y.; Bagheri, R.; Kim, Y.K.; Kim, K.-H.; Burrow, M.F. Cure mechanisms in materials for use in esthetic dentistry. J. Investig. Clin. Dent. 2012, 3, 3-16. [CrossRef] [PubMed]

7. Sideridou, I.D.; Achilias, D.S.; Kostidou, N.C. Copolymerization kinetics of dental dimethacrylate resins initiated by a benzoyl peroxide/amine redox system. J. Appl. Polym. Sci. 2008, 109, 515-524. [CrossRef]

8. Sideridou, I.D.; Achilias, D.S.; Karava, O. Reactivity of Benzoyl Peroxide/Amine System as an Initiator for the Free Radical Polymerization of Dental and Orthopedic Dimethacrylate Monomers: Effect of the Amine and Monomer Chemical Structure. Macromolecules 2006, 39, 2072-2080. [CrossRef]

9. Han, D.; Meng, Z.; Wu, D.; Zhang, C.; Zhu, H. Thermal properties of carbon black aqueous nanofluids for solar absorption. Nanoscale Res. Lett. 2011, 6, 457. [CrossRef]

10. Achilias, D.S.; Sideridou, I. Study of the Effect of Two BPO/Amine Initiation Systems on the Free-Radical Polymerization of MMA Used in Dental Resins and Bone Cements. J. Macromol. Sci. Part A 2002, 39, 1435-1450. [CrossRef]

11. Wilson, G.O.; Henderson, J.W.; Caruso, M.M.; Blaiszik, B.; McIntire, P.J.; Sottos, N.R.; White, S.R.; Moore, J.S. Evaluation of peroxide initiators for radical polymerization-based self-healing applications. J. Polym. Sci. Part A: Polym. Chem. 2010, 48, 2698-2708. [CrossRef]

12. Snider, B.B. Manganese(III)-Based Oxidative Free-Radical Cyclizations. Chem. Rev. 1996, 96, 339-364. [CrossRef]

13. Kastning, E.-G.; Naarmann, H.; Reis, H.; Berding, C. Metal Chelates as Polymerization Initiators. Angew. Chem. Int. Ed. 1965, 4, 322-327. [CrossRef] 
14. Endo, K.; Yachi, A. Molecular-weight-controlled polymerization of styrene with $\mathrm{Mn}(\mathrm{acac})_{3}$ in combination with organic halides. Polym. Bull. 2001, 46, 363-369. [CrossRef]

15. Endo, K.; Yachi, A. Polymerization of Methyl Methacrylate with Mn(acac $)_{3}$ in the Presence of Organic Halides. Possibility of Molecular Weight Control of Polymer. Polym. J. 2002, 34, 320-324. [CrossRef]

16. Nayak, P.L.; Samal, R.K.; Nayak, M.C. Aqueous Polymerization of Acrylonitrile Initiated by the $\mathrm{Mn}^{3+} / \mathrm{Citric}$ Acid Redox System. Eur. Polym. J. 1978, 14, 287-290. [CrossRef]

17. Caille, J.-R.; Debuigne, A.; Jérôme, C. Quinone transfer radical polymerization (QTRP) of styrene: Catalysis by different metal complexes. J. Polym. Sci. Part A Polym. Chem. 2005, 43, 2723-2733. [CrossRef]

18. Van Gorkum, R.; Bouwman, E.; Reedijk, J. Fast Autoxidation of Ethyl Linoleate Catalyzed by [Mn(acac) 3 ] and Bipyridine: A Possible Drying Catalyst for Alkyd Paints. Inorg. Chem. 2004, 43, 2456-2458. [CrossRef]

19. Bouwman, E.; Van Gorkum, R. A study of new manganese complexes as potential driers for alkyd paints. J. Coat. Technol. Res. 2007, 4, 491-503. [CrossRef]

20. Ligon, S.C.; Husár, B.; Wutzel, H.; Holman, R.; Liska, R. Strategies to Reduce Oxygen Inhibition in Photoinduced Polymerization. Chem. Rev. 2013, 114, 557-589. [CrossRef]

21. Garra, P.; Dumur, F.; Al Mousawi, A.; Graff, B.; Gigmes, D.; Morlet-Savary, F.; Dietlin, C.; Fouassier, J.P.; Lalevée, J. Mechanosynthesized copper(i) complex based initiating systems for redox polymerization: Towards upgraded oxidizing and reducing agents. Polym. Chem. 2017, 8, 5884-5896. [CrossRef]

22. Garra, P.; Brunel, D.; Noirbent, G.; Graff, B.; Morlet-Savary, F.; Dietlin, C.; Sidorkin, V.F.; Dumur, F.; Duché, D.; Gigmes, D.; et al. Ferrocene-based (photo)redox polymerization under long wavelengths. Polym. Chem. 2019, 10, 1431-1441. [CrossRef]

23. Garra, P.; Morlet-Savary, F.; Graff, B.; Dumur, F.; Monnier, V.; Dietlin, C.; Gigmes, D.; Lalevée, J.; Fouassier, J. Metal Acetylacetonate-Bidentate Ligand Interaction (MABLI) as highly efficient free radical generating systems for polymer synthesis. Polym. Chem. 2018, 9, 1371-1378. [CrossRef]

24. Garra, P.; Dumur, F.; Morlet-Savary, F.; Dietlin, C.; Fouassier, J.P.; Lalevée, J. A New Highly Efficient Amine-Free and Peroxide-Free Redox System for Free Radical Polymerization under Air with Possible Light Activation. Macromolecules 2016, 49, 6296-6309. [CrossRef]

25. Garra, P.; Baralle, A.; Graff, B.; Schrodj, G.; Morlet-Savary, F.; Dietlin, C.; Fouassier, J.-P.; Lalevée, J. Radical Cations in Versatile High-Performance Initiating Systems for Thermal, Redox, and Photopolymerizations. Macromolecules 2018, 51, 8899-8911. [CrossRef]

26. Wang, D.; Garra, P.; Szillat, F.; Fouassier, J.P.; Lalevée, J. Silane Based Redox Initiating Systems: Toward a Safer Amine-Free, Peroxide-Free, and Metal-Free Approach. Macromolecules 2019, 52, 3351-3358. [CrossRef]

27. Lalevée, J.; Blanchard, N.; Chany, A.C.; El-Roz, M.; Souane, R.; Graff, B.; Allonas, X.; Fouassier, J.P. Silyl Radical Chemistry and Conventional Photoinitiators: A Route for the Design of Efficient Systems. Macromolecules 2009, 42, 6031-6037.

28. Janzen, E.G.; Blackburn, B.J. Detection and identification of short-lived free radicals by electron spin resonance trapping techniques (spin trapping). Photolysis of organolead, -tin, and -mercury compounds. J. Am. Chem. Soc. 1969, 91, 4481-4490. [CrossRef]

Sample Availability: Samples of the compounds are not available from the authors.

(C) 2020 by the authors. Licensee MDPI, Basel, Switzerland. This article is an open access article distributed under the terms and conditions of the Creative Commons Attribution (CC BY) license (http://creativecommons.org/licenses/by/4.0/). 